\title{
An Echocardiographic Study of Right Ventricular Morphology and Function in Systemic Hypertension.
}

\author{
Murari Prasad Barakoti ${ }^{1}$, Adhyashree Karki², Manoj Kumar Chaulagain ${ }^{3}$, DB Karki ${ }^{3}$.
}

${ }^{1}$ Department of Cardiology, ADK Hospital, Sosun Magu, Male, Maldives.

${ }^{2}$ Department of Gastroenterology, College of Medical Sciences, Bharatput, Nepal.

${ }^{3}$ Department of Cardiology, Kathmandu Medical College Teaching Hospital, Sinamangal, Kathmandu, Nepal.

\section{Corresponding Author:}

Murari Prasad Barakoti

Department of Cardiology, ADK Hospital, Sosun Magu, Male, Maldives.

E-mail: drmuraribarakoti@gmail.com

ORCID ID: http://orcid.org/0000-0003-0698-586X

Submitted date: $27^{\text {th }}$ July 2020

Accepted date: $8^{\text {th }}$ February 2021

Cite this article as: Barakoti M P, Karki A, Chaulagain M K, et al. An Echocardiographic Study of Right Ventricular Morphology and Function in Systemic Hypertension. Nepalese Heart Journal 2021; Vol 18 (1): 39-44

\section{Abstract}

Background and Aims: Hypertension is a common medical condition that leads to increased risk of cardiovascular conditions including coronary artery disease, heart failure, stroke, renal diseases, blindness and cardiovascular death. Long term hypertension will affect left ventricle by hypertrophy and several functional derangements. Since heart works as a unit, right heart changes are expected. Right ventricular dysfunction has a strong prognostic significance and we aim to study right ventricular parameters in hypertensive patients.

Methods: We studied 71 hypertensive subjects and 66 matched control without hypertension in echocardiography laboratory for chamber dimensions and right ventricular systolic and diastolic parameters.

Results: The right ventricular free wall thickness $(5.46 \pm 1.97 \mathrm{~mm}$ vs $4.77 \pm 0.81 \mathrm{~mm} ; \mathrm{P}=0.01)$ and interventricular septal thickness $(11.62 \pm 2.64 \mathrm{~mm}$ vs $9.10 \pm 1.16 \mathrm{~mm} ; \mathrm{P}<0.01)$ were significantly higher among hypertensive patients. Right ventricular dimensions namely basal diameter $(26.41 \pm 4.97 \mathrm{~mm}$ vs $29.16 \pm 5.22 \mathrm{~mm} ; \mathrm{P}<0.01)$, mid-ventricular diameter $(25.83 \pm 4.40 \mathrm{~mm}$ vs $27.44 \pm 5.05 \mathrm{~mm} ; \mathrm{P}=0.05)$ and right ventricular long-axis length $(69.54 \pm 7.08 \mathrm{~mm}$ vs $73.28 \pm 7.08 \mathrm{~mm} ; \mathrm{P}<0.01)$ were significantly low among hypertensive patients. Tricuspid Annular Plane Systolic Excursion (TAPSE) was significantly lower among hypertensive patients $(18.84 \pm 1.85 \mathrm{~mm}$ vs control $20.54 \pm 2.65 \mathrm{~mm} ; \mathrm{P}<0.01)$. A significant statistical correlation was found between mitral $\mathrm{E} / \mathrm{A}$ ratio and tricuspid $\mathrm{E} / \mathrm{A}$ ratio (R2 linear=0.78, $\mathrm{P}=0.01$ ). Conclusion: The effect of hypertension in right ventricular structure and function are found to be subtle but definite as seen in diastolic wave velocities, right ventricular wall thickness, internal chamber dimensions and TAPSE. Assessment of hypertensive effect on heart will help to control hypertension in stringent way.

Keywords: Echocardiography; Hypertension; Right Ventricle.

DOI: https://orcid.org/10.3126/njh.v18i1.36783

\section{Introduction}

Hypertension is defined as persistent increase in blood pressure above the normal range. The prevalence increases with the age. The persistent and chronically elevated arterial pressure causes marked changes in the vasculature and heart. Hypertension is a major risk factors for coronary artery disease, and its complications, heart failure, stroke and renal insufficiency. ${ }^{1}$ Hypertension is preventable by medications and significant lifestyle modification. ${ }^{1}$ Hypertension is a common health condition that currently affects about $26 \%$ of the adults worldwide ${ }^{2}$ and is expected to rise owing to aging population, sedentary lifestyles and lower threshold for the diagnosis of hypertension, among others. The prevalence of hypertension is $21.2 \%$ among Nepalese above 15 years of age. ${ }^{3}$

Hypertension induces a progressive load to the heart causing

(a) Nepalese Heart Journal. Nepalese Heart Journal retain copyright and works is simultaneously licensed under Creative Commons Attribution License CC - By 4.0 that allows others to share the work with an acknowledge of the work's authorship and initial publication in this journal 
a gradual increase in left ventricular mass that slowly results in diastolic and systolic functional derangements. ${ }^{4}$ Human heart acts not in isolation but as a unit. ${ }^{5}$ Obviously the ranges of changes in left ventricle will have effect on the right side of the heart. Right ventricle is thin walled structure and it acts on low pressure system. There is plethora of studies about the effects and consequences of hypertension on left ventricle. Right ventricle has strong prognostic importance especially those with heart failure patients and its significance is being explored for number of different cardiac conditions. ${ }^{6}$ There are echocardiographic studies that have assessed the effects of hypertension in African and Caucacian populations showing thicker right ventricular wall, smaller right heart chambers and decreased tricuspid annular plane systolic excursion. The studies of hypertensive effect on right ventricle are sparse, if at all, in Nepalese population. The current study was designed to study right ventricular dimension, systolic and diastolic function by different echocardiographic parameters and Doppler modalities in hypertensive subjects and to compare with controls.

\section{Material and Methods}

The study was carried out in echocardiography laboratory of department of cardiology at Kathmandu Medical College Teaching Hospital from June 1, 2016 to December 30, 2016. The Research Ethics Committee of the hospital reviewed and approved the study protocol. Seventy-one hypertensive patients were compared with 66 control subjects without hypertension who attended hospital for other purposes. Hypertension was diagnosed as use of any hypertensive medications or persistent elevation of Blood Pressure (BP) $>140 / 90$ $\mathrm{mmHg}$ on two occasions on two separate days with the subject in sitting position for at least 5 minutes (as defined by World Health Organization). ${ }^{7}$ Patients with valvular heart diseases, myocardial diseases, ischemic heart diseases, congenital heart disease or cor pulmonale were excluded. Patients were subjected to history taking, physical examination and standard clinical investigations as per treating physician's discretion.

\section{Echocardiography}

All the subjects were subjected to comprehensive echocardiography with the use of Siemens ACCUSON SC 2000 ultrasonography with a 4-MHz transducer. The patients were placed in left lateral decubitus position.

Left ventricular (LV) structure, dimensions and functions were studied. LV mass was calculated using Devereux formula and LV mass index (LVMI) was derived. ${ }^{8}$ Left ventricular hypertrophy (LVH) was defined as a LVMI above $125 \mathrm{gm} / \mathrm{m}^{2}$ for both genders as used in Framingham study for the evaluation of LVH in hypertension. ${ }^{9}$ The dimensions were measured using actual blood tissue interface rather than leading edge to leading edge. Left ventricular ejection fraction was calculated with M mode measurement with Teichholz method. The pulse Doppler studies were taken from apical fourchamber or alternatively parasternal short axis view. The Doppler sample volume for right ventricle was placed at the level of tricuspid annulus. The recordings from three cycles were taken and averaged. All the recordings were taken in quite respiration. Measurements were taken as recommended by American Society of Echocardiography guidelines.

\section{Following Echocardiographic Parameters were Particularly Measured:}

- Left ventricle (LV): Interventricular septal diameter (IVSD), left ventricular end-diastolic diameter (LVEDD), Posterior wall thickness (PWT), left ventricular ejection fraction (LVEF), LV mass

- Right ventricle (RV): Right ventricular outflow tract (RVOT) diameter, basal and mid ventricular diameter, base to apex length, RV free wall thickness

- Pulmonary acceleration time

- Left atrial (LA) area, Right atrial (RA) area, Diastolic wave velocities: E, A wave, E/A ratio, tissue Doppler velocities: e', E/e`

- Tricuspid annular plane systolic excursion (TAPSE)

- Tricuspid diastolic wave velocities: Tricuspid E, A, E/A, right ventricular tissue Doppler velocities: RV s', e', a'

Statistical Analysis

Data were analyzed using IBM SPSS Statistics version 20. Quantitative data were summarized using mean +/- standard deviation. Comparison for numerical variables was done using t-test for independent samples. Correlation analysis was done for some diastolic and systolic variables. Statistical significance is taken as $\mathrm{P}<0.05$.

\section{Results}

Age and gender were similar in both groups. Body mass index and mean heart rate were also similar. As expected, systolic and diastolic BP were significantly higher in the hypertensive subjects compared to controls.

Table 1: Baseline characteristics among study population.

\begin{tabular}{|llll|}
\hline & Hypertensive & $\begin{array}{l}\text { Control } \\
(\mathbf{N}=66)\end{array}$ & P value \\
\hline $\begin{array}{l}\text { Mean Age } \\
\text { (Years) }\end{array}$ & $53.06 \pm 9.92$ & $50.70 \pm 7.84$ & 0.13 \\
$\begin{array}{l}\text { Mean BMI } \\
\left(\mathrm{Kg} / \mathrm{m}^{2}\right)\end{array}$ & $24.92 \pm 4.13$ & $24.26 \pm 4.43$ & 0.36 \\
\hline Mean BSA $\left(\mathrm{m}^{2}\right)$ & $1.66 \pm 0.19$ & $1.66 \pm 0.18$ & 0.99 \\
\hline $\begin{array}{l}\text { Mean SBP } \\
(\mathrm{mmHg})\end{array}$ & $140.99 \pm 19.51$ & $118.33 \pm 10.32$ & $<0.01$ \\
\hline $\begin{array}{l}\text { Mean DBP } \\
(\mathrm{mmHg})\end{array}$ & $88.90 \pm 10.04$ & $75.70 \pm 7.72$ & $<0.01$ \\
\hline $\begin{array}{l}\text { Mean HR } \\
(\mathrm{bpm})\end{array}$ & $79.79 \pm 12.68$ & $77.41 \pm 8.38$ & 0.20 \\
\hline
\end{tabular}

As shown in table 2, the echocardiographic parameters show significant variations between hypertensive patients and controls. The LV wall dimensions and LV mass index were significantly higher in the 
hypertensive subjects. Aortic dimension was increased significantly in hypertensive patients. The left atrial diameter was similar between the groups but left atrial area measured in four-chamber view was significantly higher in hypertensive patients compared to the control. The diastolic early (E wave) and E/A ratio were similar, but the E/e ratio was significantly higher among hypertensive subjects.

Table 2: Left ventricular echocardiographic parameters of study participants.

\begin{tabular}{|c|c|c|c|}
\hline & $\begin{array}{l}\text { Hypertensive } \\
(\mathrm{N}=71)\end{array}$ & $\begin{array}{l}\text { Control } \\
(\mathrm{N}=66)\end{array}$ & P value \\
\hline $\begin{array}{l}\text { Mean IVS Diameter } \\
(\mathrm{mm})\end{array}$ & $11.62 \pm 2.64$ & $9.10 \pm 1.16$ & $<0.01$ \\
\hline $\begin{array}{l}\text { Mean PW Diameter } \\
(\mathrm{mm})\end{array}$ & $11.59 \pm 2.70$ & $8.97 \pm 1.34$ & $<0.01$ \\
\hline $\begin{array}{l}\text { Mean LVMI } \\
(\mathrm{gm} / \mathrm{m} 2)\end{array}$ & $125.81 \pm 12.83$ & $97.22 \pm 9.64$ & $<0.01$ \\
\hline Mean EF (\%) & $67.85 \pm 5.75$ & $67.47 \pm 5.64$ & 0.70 \\
\hline $\begin{array}{l}\text { Mean Aorta } \\
\text { Diameter }(\mathrm{mm})\end{array}$ & $29.12 \pm 5.21$ & $26.11 \pm 3.58$ & $<0.01$ \\
\hline $\begin{array}{l}\text { Mean LA } \\
\text { Diameter }(\mathrm{mm})\end{array}$ & $31.36 \pm 4.66$ & $31.19 \pm 4.38$ & 0.83 \\
\hline Mean LA area $\left(\mathrm{mm}^{2}\right)$ & $15.85 \pm 3.02$ & $11.15 \pm 2.88$ & $<0.01$ \\
\hline Mean Mitral E (m/s) & $0.66 \pm 0.16$ & $0.66 \pm 0.16$ & 0.74 \\
\hline Mean Mitral A (m/s) & $0.77 \pm 0.17$ & $0.68 \pm 0.13$ & $<0.01$ \\
\hline Mean Mitral E/A & $0.93 \pm 0.46$ & $1.00 \pm 0.32$ & 0.31 \\
\hline $\begin{array}{l}\text { Mean Mitral decT } \\
(\mathrm{msec})\end{array}$ & $150.92 \pm 48.03$ & $140.18 \pm 36.68$ & 0.15 \\
\hline $\begin{array}{l}\text { Mean LV Medial e' } \\
(\mathrm{m} / \mathrm{s})\end{array}$ & $0.09 \pm 0.09$ & $0.09 \pm 0.02$ & 0.86 \\
\hline Mean Mitral E/e` & $8.42 \pm 2.33$ & $7.70 \pm 2.03$ & 0.05 \\
\hline
\end{tabular}

Table 3 shows two dimensional and Doppler echocardiographic measurements of right side in hypertensive and control subjects. Pulmonary valve peak velocity was higher and acceleration time was lower among hypertensive patients compared to control population. Right ventricular outflow tract diameter and pulmonary artery diameter were similar. Tricuspid diastolic early (E wave) and atrial (A wave) velocities were similar too, but tricuspid annular plane systolic excursion (TAPSE) was already lower in hypertensive subject though still under normal limit.

Our results show the right ventricular basal diameter, mid-level diameter and base-to-apex length lower among hypertensive subjects. Right ventricular free wall thickness measured in sub-xyphoid view was significantly high in hypertensive subjects. RV wall thickness has positive correlation with systolic $\mathrm{BP}$ but not diastolic $\mathrm{BP}(\mathrm{P}=0.03$ for $\mathrm{SBP}, \mathrm{P}=0.09$ for $\mathrm{DBP}$ ). As we investigated hypertensive patients, those with left ventricular hypertrophy (defined as $>125 \mathrm{gm} / \mathrm{m} 2$ ) has significantly different $\mathrm{E} / \mathrm{A}$ ratio (diastolic dysfunction) $(0.84+/-0.28$ vs. $1.05+/-0.4 ; \mathrm{P}=0.013)$. A significant statistical correlation was found between mitral E/A ratio and tricuspid $\mathrm{E} / \mathrm{A}$ ratio.
Table 3: Right ventricular echo and doppler parameters among study participants.

\begin{tabular}{|c|c|c|c|}
\hline & $\begin{array}{l}\text { Hypertensive } \\
(\mathrm{N}=71)\end{array}$ & $\begin{array}{l}\text { Control } \\
(N=66)\end{array}$ & $\begin{array}{l}P \\
\text { value }\end{array}$ \\
\hline $\begin{array}{l}\text { Mean Max Pulmo } \\
\text { Velocity }(\mathrm{m} / \mathrm{s})\end{array}$ & $0.88 \pm 0.19$ & $0.80 \pm 0.14$ & 0.01 \\
\hline Mean PV accT (msec) & $125.72 \pm 24.13$ & $134.06 \pm 21.91$ & 0.04 \\
\hline $\begin{array}{l}\text { Mean RVOT Diameter } \\
(\mathrm{mm})\end{array}$ & $24.58 \pm 2.97$ & $24.68 \pm 2.85$ & 0.84 \\
\hline $\begin{array}{l}\text { Mean PA } \\
\text { Diameter }(\mathrm{mm})\end{array}$ & $21.87 \pm 3.10$ & $21.51 \pm 2.78$ & 0.48 \\
\hline Mean RA area $\left(\mathrm{mm}^{2}\right)$ & $12.27 \pm 2.59$ & $10.22 \pm 2.70$ & $<0.01$ \\
\hline Mean TV E (m/s) & $0.45 \pm 0.11$ & $0.45 \pm 0.13$ & 0.83 \\
\hline Mean TV A (m/s) & $0.52 \pm 0.14$ & $0.49 \pm 0.12$ & 0.17 \\
\hline Mean TAPSE (mm) & $18.84 \pm 1.85$ & $20.54 \pm 2.65$ & $<0.01$ \\
\hline Mean RV E’(m/s) & $0.11 \pm 0.10$ & $0.12 \pm 0.03$ & 0.72 \\
\hline Mean RV A`(m/s) & $0.17 \pm 0.05$ & $0.16 \pm 0.04$ & 0.04 \\
\hline Mean RV S'(m/s) & $0.15 \pm 0.03$ & $0.14 \pm 0.07$ & 0.50 \\
\hline $\begin{array}{l}\text { Mean RV Basal } \\
\text { Diameter }(\mathrm{mm})\end{array}$ & $26.41 \pm 4.97$ & $29.16 \pm 5.22$ & $<0.01$ \\
\hline $\begin{array}{l}\text { Mean RV Mid } \\
\text { Diameter (mm) }\end{array}$ & $25.83 \pm 4.40$ & $27.44 \pm 5.05$ & 0.05 \\
\hline $\begin{array}{l}\text { Mean RV Length } \\
(\mathrm{mm})\end{array}$ & $69.54 \pm 7.08$ & $73.28 \pm 7.08$ & $<0.01$ \\
\hline $\begin{array}{l}\text { Mean RV Wall } \\
\text { Thickness (mm) }\end{array}$ & $5.46 \pm 1.97$ & $4.77 \pm 0.81$ & 0.01 \\
\hline
\end{tabular}

Table 4: Right ventricular echo and doppler parameters among hypertensive patients.

\begin{tabular}{|llll}
\hline & $\begin{array}{l}\text { Hypertension } \\
\text { with LVH } \\
(\mathbf{N = 3 9 )}\end{array}$ & $\begin{array}{l}\text { Hypertension } \\
\text { without LVH } \\
(\mathbf{N = 3 2})\end{array}$ & $\begin{array}{l}\text { P } \\
\text { value }\end{array}$ \\
\hline Mean RA area $\left(\mathrm{mm}^{2}\right)$ & $12.25 \pm 2.28$ & $12.29 \pm 2.96$ & 0.95 \\
\hline Mean TV E (m/s) & $0.44 \pm 0.08$ & $0.48 \pm 0.14$ & 0.13 \\
\hline Mean TV A(m/s) & $0.55 \pm 0.13$ & $0.49 \pm 0.15$ & 0.06 \\
\hline Mean TV E/A (m/s) & $0.84 \pm 0.28$ & $1.05 \pm 0.40$ & 0.01 \\
\hline Mean TAPSE (mm) & $18.71 \pm 2.09$ & $18.99 \pm 1.52$ & 0.53 \\
\hline Mean RV E'(m/s) & $0.12 \pm 0.13$ & $0.10 \pm 0.03$ & 0.38 \\
\hline Mean RV A'(m/s) & $0.18 \pm 0.06$ & $0.17 \pm 0.04$ & 0.47 \\
\hline Mean RV S'(m/s) & $0.15 \pm 0.03$ & $0.14 \pm 0.03$ & 0.08 \\
\hline $\begin{array}{l}\text { Mean RV Basal } \\
\text { Diameter (mm) }\end{array}$ & $26.76 \pm 5.06$ & $25.98 \pm 4.90$ & 0.51 \\
\hline $\begin{array}{l}\text { Mean RV mid Diameter } \\
\text { (mm) }\end{array}$ & $25.96 \pm 4.48$ & $25.67 \pm 4.37$ & 0.78 \\
\hline $\begin{array}{l}\text { Mean RV Length (mm) } \\
\text { Mean RVOT Diameter } \\
\text { (mm) }\end{array}$ & $69.17 \pm 7.94$ & $70.00 \pm 5.97$ & 0.62 \\
\hline
\end{tabular}


Figure 1: Correlation of right ventricular free wall thickness with BP showing significant correlation with systolic $(\mathrm{P}=0.038)$ and not with Diastolic BP $(\mathrm{P}=0.094)$.
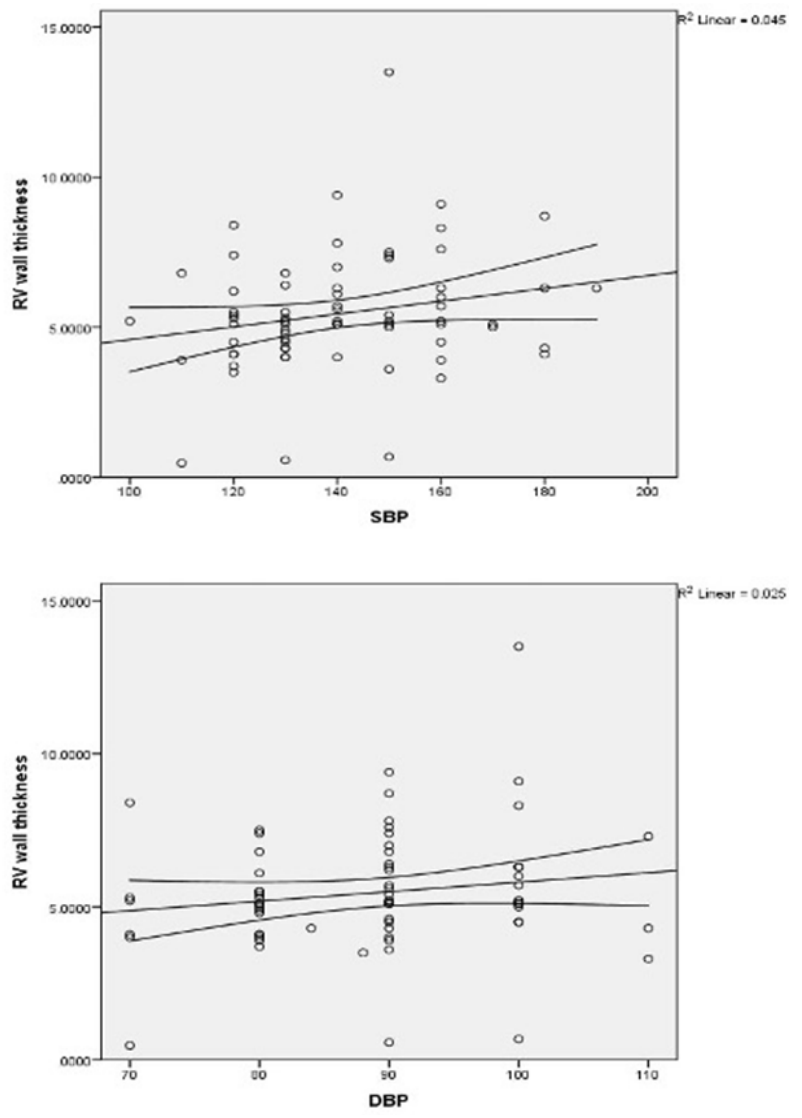

Figure 2: Correlation of tricuspid diastolic flow with mitral diastolic flow (E/A ratio) showing significant positive correlation $(\mathrm{P}=0.018)$.

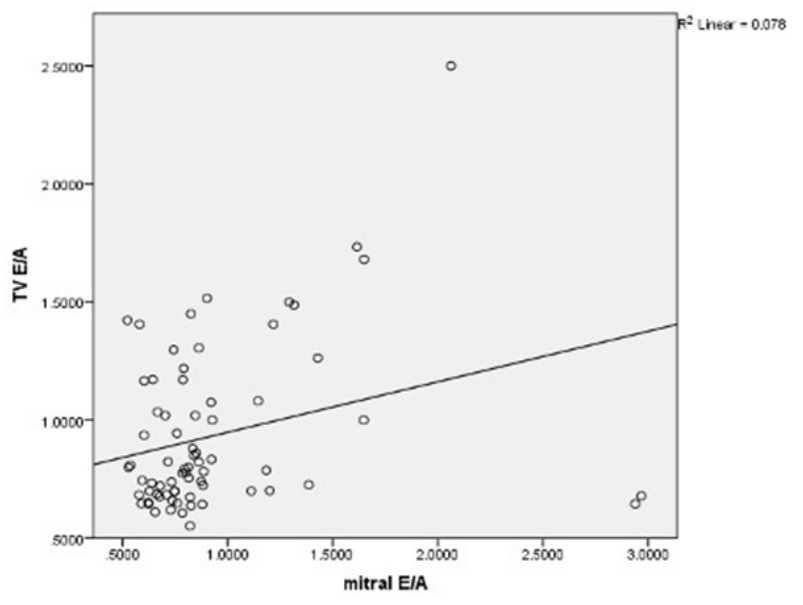

\section{Discussion}

The study showed that right ventricular diastolic dysfunction accompanies left ventricular dysfunction in hypertensive patients. This is in agreement with studies in Caucasian and African population. ${ }^{10-12}$ Right ventricular structural changes occur in hypertensive heart disease.
Our study showed that the interventricular septal and posterior wall thickness were significantly higher, though it may not fulfill the criteria of hypertrophy. This is similar to findings as studied by Akintunde et al in Nigerian population. ${ }^{11}$ Left ventricular mass index was significantly higher in hypertensive patients $(125.82 \pm 12.83$ in hypertensive vs $97.22 \pm 9.64$ in control; $\mathrm{P}<0.01$ ) with the caveat of the accuracy of such measurement. Mean LVMI was $121.1 \mathrm{gm} / \mathrm{m}^{2}$ in hypertensive patients vs $87.6 \mathrm{gm} / \mathrm{m}^{2}$ in normotensive individuals in the study done by Akintunde. ${ }^{11}$ Similarly, right ventricular hypertrophy in form of increased free wall thickness was significantly more common in hypertensive subjects. Nunez et al has demonstrated that right ventricular hypertrophy does occur in hypertensive patients. ${ }^{13}$ In another study, hypertensives patients had thicker right ventricular wall (5.3mm vs $2.8 \mathrm{~mm} ; \mathrm{P}<0.01) .{ }^{14}$ Our study showed similar findings with free wall right ventricle thickness increased in hypertensive patients (5.46mm vs $4.77 \mathrm{~mm} ; \mathrm{P}=0.01$ ). An echocardiographic study of hypertensive effect on African population by Akintunde et al showed right ventricular dimensions decreased in hypertensive patients. ${ }^{11}$ This is likely due to increased wall thickness of interventricular septum and RV free wall. The results in our study were similar. We measured basal and mid-level dimension as well as longitudinal length and all parameters were found to be decreased in hypertensive patients. The explanation of this could be attributed to the prolonged exposure to hypertension will lead to muscle hypertrophy and chamber reduction before progressive dilatation may occur in the right heart. ${ }^{11}$ This has to be tested with the duration of hypertension and the effects may be different with different level of BP, duration of hypertension and use of specific antihypertensive medication. Further research is required to find out the relationship.

Our study showed statistically significant increased flow in mean pulmonary systolic velocity between hypertensive subjects and control $(0.84 \mathrm{~m} / \mathrm{s}$ vs $0.8 \mathrm{~m} / \mathrm{s} ; \mathrm{P}=0.01)$. This is expected to see alteration in right ventricular pressure changes influenced by pressure and volume changes associated with hypertension. This is in contrast with the study done in Nigeria who failed to demonstrate the changes. ${ }^{11}$ The likely explanation they give was hypertension could take different time period to have effect on right and left ventricles.

Increased distension of one ventricle during diastole will change the compliance and geometry of the opposite ventricle either due to direct mechanical effect or some other indirect effects. ${ }^{15}$ Ventricular interdependence is defined as forces that are transmitted from one to another ventricle, independent of neural, humoral or circulatory effects. It is because both ventricles share common muscle bundle, septum and pericardium. ${ }^{16,17}$ The mechanism of ventricular interaction is mainly related to restriction of ventricular fillings by the pericardium. ${ }^{18}$ This suggests that hypertension will affect both ventricles.

Doppler studies of cardiac blood flow and tissue movement represent echocardiographic parameters to assess diastolic function. Several prior studies have shown that hypertension causes left ventricular diastolic dysfunction early. There is reduction of early $\mathrm{E}$ wave and relative increase in A wave amplitude. This may be followed by severe changes in diastolic function including restrictive pattern. ${ }^{15}$ The current study showed higher A wave velocity in hypertensive patients suggestive of higher prevalence of diastolic dysfunction although in subtle level (A velocity in hypertensive vs control 0.77 $\mathrm{m} / \mathrm{s}$ vs $0.68 \mathrm{~m} / \mathrm{s} ; \mathrm{P}<0.01)$. The study results are similar to findings by Akintunde et al (A velocity in hypertensive $0.68 \mathrm{~m} / \mathrm{s}$ vs $0.54 \mathrm{~m} / \mathrm{s}$ in control: $\mathrm{P}<0.05){ }^{11}$

The study assessed some parameters of right ventricular systolic function viz transannular plane systolic excursion or TAPSE. Despite being within normal limit, TAPSE was significantly lower among hypertensive patients. This means that RV systolic function may deteriorate over time and is of prognostic significance. In a study 
of patients with mean LVEF $22( \pm 7) \%$, resting RVEF $(>35 \%)$ was shown to be the most powerful independent predictor of survival in a multivariate model that included the other conventional prognostic markers (LVEF, peak $\dot{V}_{2}$, peak percentage age and sex adjusted $\dot{V}_{\mathrm{o}_{2}}$, left ventricular end diastolic volume index, left ventricular end systolic volume index, and cardiac index). ${ }^{17}$ In a study done in Egypt, TAPSE was reduced in hypertensive patients $18.8 \mathrm{~mm}$ versus $22 \mathrm{~mm}$ in healthy group $(\mathrm{P}<0.001)$. Our study revealed similar results with lower TAPSE in hypertensive patients $(18.8$ vs $20.5 ; \mathrm{P}<0.01) .{ }^{12}$ The current study demonstrated similar pattern of tricuspid wave velocities and mitral wave velocities with good statistical correlation $(\mathrm{P}=0.018)$. Similar findings were observed in a study in Africa. ${ }^{11}$ This suggests that the right ventricular diastolic function is affected by hypertension like left ventricular diastolic function. The changes may be quite subtle in the early stage of disease and may require use of more specific diagnostic imaging modalities and novel technology and parameters such as tissue doppler imaging and strain echocardiography or cardiac MRI for instance.

There were few limitations of the study. This is a single center study. Measurement after capture of image by an echocardiographer unknown to the study group assignment could reduce some of the bias. However, it is not practiced in our hospital due to logistic issues. Correlating with more accurate and specific imaging techniques including cardiac MRI or speckle tracking modalities could be more accurate and consistent to find out the subtle differences. Other limitation was we only measured TAPSE for RV systolic function, other parameters like lateral S' and fractional area changes are not measured. However, using the current standard of care in our setting has served as an eye-opener to see the effect of hypertension in right ventricular morphology and function.

\section{Conclusions}

Hypertension also affects structure and function of right ventricle in addition to left ventricle. The changes are subtle but definite. Our study demonstrated changes in diastolic wave velocities, right ventricular wall thickness and internal chamber dimensions. Knowing the effects would help clinicians and patients for stringent control of blood pressure.

\section{Acknowledgements}

The authors express special thankfulness to all the study participants. The authors mention special thanks to then interns and medical officers in department of cardiology for tremendous support during data collection. The assistance of staff members of echocardiography lab of KMC including Krishna Kumari Thapa, Ganga Pradhanaga Baidhya, Sunita Khanal and Sajana Bajagain is highly appreciated.

\section{Conflicts of interest: None}

\section{Abbreviations}

ACC:American college of cardiology; AHA:American heart association; LV:Left ventricle/ventricular; LVMI:left ventricular mass index; BP: blood pressure; LVH: left ventricular hypertrophy; TAPSE: Tricuspid annular plane systolic excursion; SBP: systolic blood pressure; DBP:diastolic blood pressure; RV:Right ventricle/ ventricular;

\section{References}

1. Messerli FH, Fischer U, Rimoldi SF, et al. Hypertension control and cardiovascular disease. Lancet 2017;389(10065):153.

https://doi.org/10.1016/S0140-6736(17)30017-X

2. Kearney P, Whelton M, Reynolds K, et al. Global Burden of Hypertension: Analysis of Worldwide Data. Lancet 2005;365:217-23. https://doi.org/10.1016/S0140-6736(05)17741-1

3. Kibria GMA, Swasey K, KC A, et al. Estimated Change in Prevalence of Hypertension in Nepal Following Application of the 2017 ACC/AHA Guideline. JAMA Network Open 2018;1(3):e180606-e. https://doi.org/10.1001/jamanetworkopen.2018.0606

4. Ganau A, Devereux RB, Roman MJ, et al. Patterns of left ventricular hypertrophy and geometric remodeling in essential hypertension. J Am Coll Cardiol 1992;19(7):1550-8. https://doi.org/10.1016/0735-1097(92)90617-V

5. Clyne CA, Alpert JS, Benotti JR. Interdependence of the left and right ventricles in health and disease. AmHeart J1989;117(6):1366-73. https://doi.org/10.1016/0002-8703(89)90418-3

6. Bleasdale RA, Frenneaux MP. Prognostic importance of right ventricular dysfunction. Heart. 2002;88(4):323-324. https://doi.org/10.1136/heart.88.4.323

7. Devereux RB, Alonso DR, Lutas EM, et al. Echocardiographic assessment of left ventricular hypertrophy: Comparison to necropsy findings. Am J Cardiol 1986;57(6):450-8. https://doi.org/10.1016/0002-9149(86)90771-X

8. Levy D, Savage DD, Garrison RJ, et al. Echocardiographic criteria for left ventricular hypertrophy: The Framingham heart study. Am J Cardiol1987;59(9):956-60. https://doi.org/10.1016/0002-9149(87)91133-7

9. Olivari MT, Fiorentini C, Polese A, Guazzi MD. Pulmonary hemodynamics and right ventricular function in hypertension. Circulation 1978;57(6):1185-90. https://doi.org/10.1161/01.CIR.57.6.1185

10. Akintunde AA, Akinwusi PO, Familoni OB, et al. Effect of systemic hypertension on right ventricular morphology and function: an echocardiographic study. Cardiovasc J Afr 2010;21(5):252-6.

https://doi.org/10.5830/CVJA-2010-013

11. Hanboly N. Right ventricle morphology and function in systemic hypertension. Nig J Cardiol 2016;13(1):11-7. https://doi.org/10.4103/0189-7969.173854

12. Nunez BD, Messerli FH, Amodeo C, et al. Biventricular cardiac hypertrophy in essential hypertension. Am Heart J 1987;114(4, Part 1):813-8.

https://doi.org/10.1016/0002-8703(87)90792-7 
13. Hanboly NH. Right ventricle morphology and function in systemic hypertension. Nig J Cardiol 2016;13:11-7. https://doi.org/10.4103/0189-7969.173854

14. Santamore WP, Gray L, Jr. Significant left ventricular contributions to right ventricular systolic function. Mechanism and clinical implications. Chest 1995;107(4):1134-45. https://doi.org/10.1378/chest.107.4.1134

15. Fagard R, Lijnen P, Staessen J, et al. The pulmonary circulation in essential systemic hypertension. AmJ Cardiol 1988;61(13):1061-5

https://doi.org/10.1016/0002-9149(88)90126-9

16. Di Salvo TG, Mathier M, Semigran MJ, Dec GW. Preserved right ventricular ejection fraction predicts exercise capacity and survival in advanced heart failure. J Am Coll Cardiol. 1995 Apr;25(5):1143-53.

https://doi.org/10.1016/0735-1097(94)00511-n

17. Fiorentini C, Folli C, Galli C, et al. Pulmonary vascuar overreactivity in systemic hypertension. Hypertension 1985; 7: $995-1002$.

https://doi.org/10.1161/01.HYP.7.6.995

18. Masud H K, Raul E E, Rick A N, et al. Pericardial disease: diagnosis and management. Mayo Clin Proc.2010;85(6):572593.

https://doi.org/10.4065/mcp.2010.0046 